\title{
Detection of Co-Infection of Notocactus leninghausii f. cristatus with Six Virus Species in South Korea
}

\author{
Chung Hwa Park ${ }^{\dagger}$ Eun Gyeong Song ${ }^{\dagger}$, and Ki Hyun Ryu* \\ Plant Virus GenBank, Department of Horticulture, Biotechnology and Landscape Architecture, Seoul Women's Univer- \\ sity, Seoul 01797, Korea
}

(Received on August 24, 2017; Revised on October 17, 2017; Accepted on October 29, 2017)

Co-infection with two virus species was previously reported in some cactus plants. Here, we showed that Notocactus leninghausii f. cristatus can be co-infected with six different viruses: cactus mild mottle virus (CMMoV)-Nl, cactus virus X (CVX)-Nl, pitaya virus $\mathrm{X}$ (PiVX)-Nl, rattail cactus necrosis-associated virus (RCNaV)-Nl, schlumbergera virus X (SchVX)-Nl, and zygocactus virus $\mathrm{X}(\mathrm{ZyVX})-\mathrm{Nl}$. The coat protein sequences of these viruses were compared with those of previously reported viruses. CMMoV-NI, CVX-Nl, PiVX-NI, RCNaV-Nl, SchVX-Nl, and ZyVX-NI showed the greatest nucleotide sequence homology to $\mathrm{CMMoV}$ Kr (99.8\% identity, GenBank accession NC_011803), CVX-Jeju (77.5\% identity, GenBank accession LC12841), PiVX-P37 (98.4\% identity, GenBank accession NC_024458), RCNaV (99.4\% identity, GenBank accession NC_016442), SchVX-K11 (95.7\% identity, GenBank accession NC_011659), and ZyVX-B1 (97.9\% identity, GenBank accession NC_006059), respectively. This study is the first report of co-infection with six virus species in N. leninghausii f. cristatus in South Korea.

Keywords : Notocactus leninghausii f. cristatus, potexvirus, tobamovirus

Handling Associate Editor : Lim, Hyoun-Sub

\footnotetext{
These authors contributed equally to this work as first authors.

*Corresponding author.

Phone) +82-2-970-5618, FAX) +82-2-970-5610

E-mail)ryu@swu.ac.kr

(c) This is an Open Access article distributed under the terms of the Creative Commons Attribution Non-Commercial License (http:// creativecommons.org/licenses/by-nc/4.0) which permits unrestricted noncommercial use, distribution, and reproduction in any medium, provided the original work is properly cited.
}

Articles can be freely viewed online at www.ppjonline.org.
Cacti are succulent plants within the family Cactaceae and are often used as ornamental plants. Cactus plants can be infected by various viruses, such as cactus mild mottle virus (CMMoV), detected from Gymnocalycium mihanovichii in South Korea; cactus virus 2 (CV2), detected from Mammillaria elongata f. cristata in Ukraine; cactus virus X (CVX), detected from Zygocactus sp. in Yugoslavia, Platyopuntia chlorotica in the USA, Cereus sp., Echinocererus sp., Lobibia sp., Nopalea cochenillifera, Mamillaria sp., Opuntia sp., Pereskia sp., and Zygocactus truncatum in Brazil, and Hylocereus spp. in South Korea, China, and Taiwan; opuntia virus X (OpVX), detected from Opuntia sp. in the USA; rattail cactus necrosis-associated virus ( $\mathrm{RCNaV})$, detected from Aporcactus flagelliformis in South Korea; sammon's Opuntia virus (SOV), detected from Opuntia sp. in the USA; saguaro cactus virus (SCV), detected from Carnegiea gigantea in the USA and Hylocereus trigonus in South Korea; schlumbergera virus X (SchVX), detected from Schlumbergera bridgesii in Yugoslavia; tomato spotted wilt virus (TSWV), detected from Opuntia sp. and Schlumbergera trancata in the USA; and zygocactus virus $\mathrm{X}(\mathrm{ZyVX})$, detected from Zygocactus sp. in Yugoslavia (Aragao et al., 1993; Hausbeck et al., 1992; Kim et al., 2012; Koenig et al., 2004; Lim et al., 2016; Liou et al., 2001; Maliarenko and Mudrak, 2013; Milbrath and Melson et al., 1972; Milbrath et al., 1973; Min et al., 2006; SuasteDzul et al., 2012). Pitaya virus X (PiVX), isolated from Hylocereus sp. (pitaya) in Taiwan, was recently reported in the NCBI nucleotide database. The viruses mentioned above can be divided into five genera: Tobamovirus, including $\mathrm{CMMoV}, \mathrm{RCNaV}$, and $\mathrm{SOV}$; Carlavirus including CV2; Potexvirus, including CVX, OpVX, SchVX, PiVX, and ZyVX; Carmovirus, including SCV; and Tospovirus, including TSWV.

Co-infections of some cactus-infecting viruses were reported in Platyopuntia chlorotica, Mammillaria elonga $\mathrm{f}$. 
cristata, and Opuntia basillaris cacti and the viruses exhibited particles corresponding to tobamovirus (SOV)-like and potexvirus-like structures (CVX or ZyVX) under electron microscopy (Chessin and Lesemann, 1972; Maliareko and Mudrak, 2013; Milbrath et al., 1973).

Based on these findings, we collected 84 cacti samples from cactus farms and fields in four provinces (Gyeonggi, Gangwon, Chungcheong and Jeju) in South Korea and investigated the co-infection of cactus plants with various viruses by electron microscopy and RT-PCR analysis from previously unpublished studies. In the investigated cactus plants, only Notocactus leninghausii f. cristatus, obtained from a cactus farm in Gyeonggi province, was coinfected with various viruses. In this study, we identified the viral co-infections in $N$. leninghausii f. cristatus. The $N$. leninghausii $\mathrm{f}$. cristatus did not exhibit the typical virus symptoms of mosaic and mottle, chlorotic spots, necrosis, stunting, or distortion. Electron microscopy analysis was performed using a method modified from that described by Min et al. (2006) at NISEM (Seoul National University, http://www.nicem.snu.ac.kr/). Here, crude cactus sap was used for analysis rather than purified virus as described in the original method. In the sap of asymptomatic $N$. lening- hausii f. cristatus (Fig. 1A), we were able to observe virus particles, such as rod-shaped and filamentous virions (Fig. 1B) typical of tobamovirus (320 nm in length and $18 \mathrm{~nm}$ in width) and potexvirus (580 nm in length and $13 \mathrm{~nm}$ in width), respectively, as previously reported (Maliareko and Mudrak, 2013; Milbrath et al., 1973; Min et al., 2006).

To confirm co-infection with tobamovirus and potexvirus in N. leninghausii f. cristatus, specific primers for detecting the gene encoding the coat proteins (CPs) of two tobamoviruses $(\mathrm{CMMoV}$ and $\mathrm{RCNaV})$ and five potexviruses (CVX, OpVX, PiVX, SchVX and ZyVX) were designed using the NCBI nucleotide database (NC_011803, NC_002815, LC128411, JF937699, NC_006060, NC_024458, NC_016442, KU854932, NC_011659, KÜ854929, KP090203, NC_006059, JF930326) with Lasergene software (DNA Star Inc., Wl, USA) (Table 1). Total RNA of the cactus plants was used for RT-PCR analysis. Total RNA was purified using the RNeasy Plant Mini Kit (Qiagen, Valencia, CA, USA) according to the manufacturer's instructions, followed by a reverse transcription (RT) reaction using the RevertAid First Strand cDNA synthesis kit (Thermo Fisher Scientific, Pittsburgh, PA, USA). PCR products were amplified using a thermocycler (MyCycler,
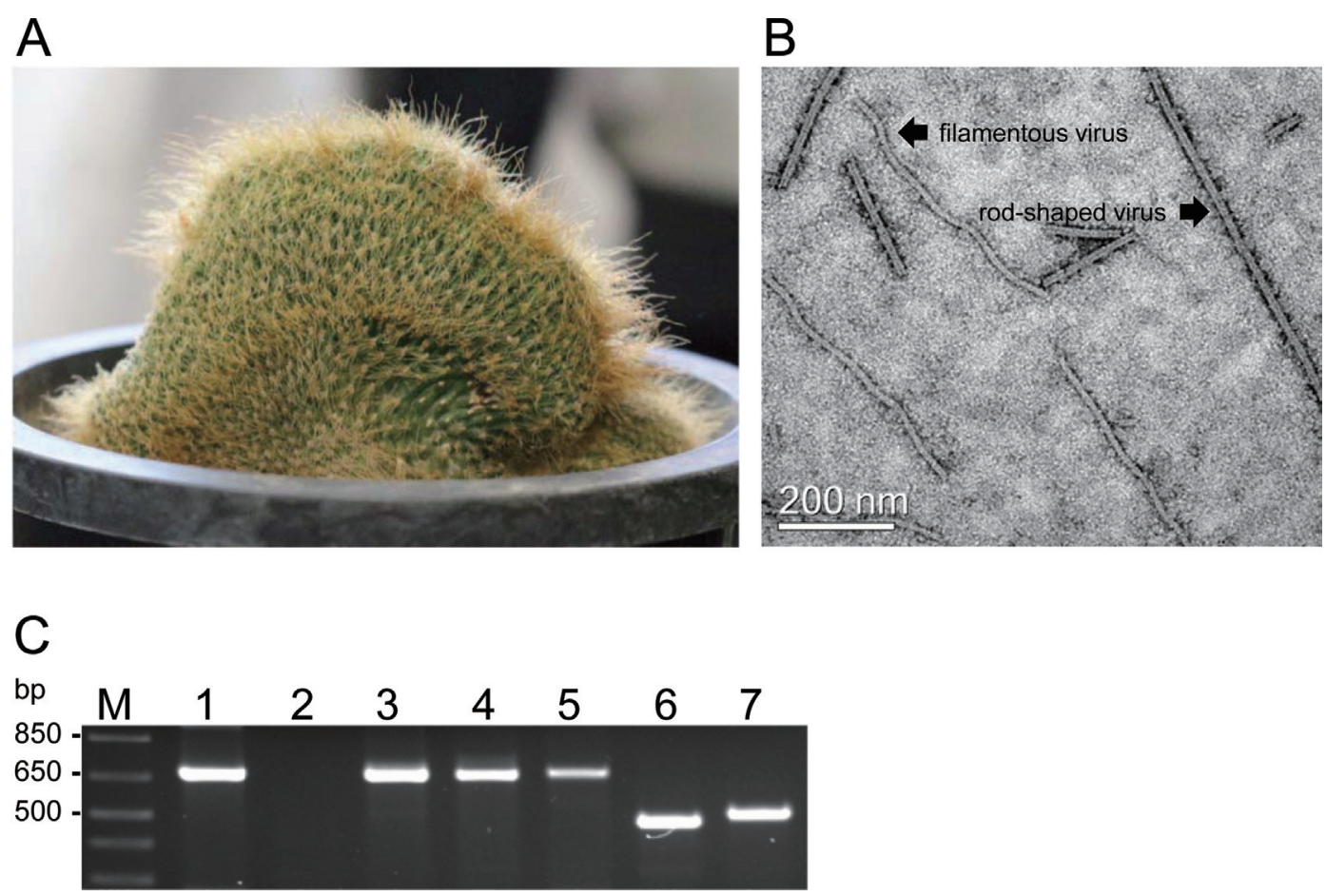

Fig. 1. Detection of cactus-infecting viruses in Notocactus leninghausii f. cristatus. (A) N. leninghausii f. cristatus. (B) Rod-shaped and filamentous particles in the sap of $N$. leninghausii f. cristatus observed by electron microscopy. Bar represents $200 \mathrm{~nm}$. (C) RT-PCR analysis of the coat proteins (CPs) of cactus-infecting viruses amplified using specific primers from total RNA isolated from $N$. leninghausii f. cristatus. Lane M: 1 kb plus DNA ladder; lane 1: CVX, 678 bp; lane 2: OpVX, 690 bp; lane 3: PiVX, 678 bp; lane 4: SchVX, 678 bp; lane 5: ZyVX, 681 bp; lane 6: CMMoV, 486 bp; lane 7: RCNaV, 513 bp. 
Table 1. Primers used in RT-PCR analysis for virus detection

\begin{tabular}{|c|c|c|c|c|c|c|}
\hline Virus & Name & Sequences ( $5^{\prime}$ to $\left.3^{\prime}\right)$ & $\begin{array}{l}\text { Base } \\
\text { pairs }\end{array}$ & $\begin{array}{l}\text { Product } \\
\text { size (bp) }\end{array}$ & $\begin{array}{l}\text { Target } \\
\text { gene }\end{array}$ & $\begin{array}{c}\text { Annealing } \\
\text { temperature }\left({ }^{\circ} \mathrm{C}\right)\end{array}$ \\
\hline \multirow{2}{*}{ CVX } & CVX 678 UP & ATG TCT ACT ACT GGA GTC CA & 20 & \multirow{2}{*}{678} & \multirow{2}{*}{$\mathrm{CP}$} & \multirow{2}{*}{58} \\
\hline & CVX $678 \mathrm{DN}$ & CTA CTC AGG GCC TGG GAG AA & 20 & & & \\
\hline \multirow{2}{*}{$\mathrm{CMMoV}$} & CMMoV 486 UP & ATG GCG GGT TCT TAC ACC AA & 20 & \multirow{2}{*}{486} & \multirow{2}{*}{$\mathrm{CP}$} & \multirow{2}{*}{57} \\
\hline & CMMoV 486 DN & CTA GGT GTG GCA CCT AAG GT & 20 & & & \\
\hline \multirow{2}{*}{ OpVX } & OpVX 690 UP & ATG GCT TCC ACT CCA CAG AC & 20 & \multirow{2}{*}{690} & \multirow{2}{*}{$\mathrm{CP}$} & \multirow{2}{*}{57} \\
\hline & OpVX 690 DN & TTA TTC AGG ACC TGG TAG GA & 20 & & & \\
\hline \multirow{2}{*}{ PiVX } & PiVX 678 UP & ATG GCT ACT CAA ACA GCA CAA & 21 & \multirow{2}{*}{678} & \multirow{2}{*}{$\mathrm{CP}$} & \multirow{2}{*}{57} \\
\hline & PiVX 678 DN & CTA CTC TGG GGA GGG AAG & 18 & & & \\
\hline \multirow{2}{*}{$\mathrm{RCNaV}$} & RCNaV 513 UP & ATG CCT TAC ATC AAC GTA CA & 20 & \multirow{2}{*}{513} & \multirow{2}{*}{$\mathrm{CP}$} & \multirow{2}{*}{55} \\
\hline & $\mathrm{RCNaV} 513 \mathrm{DN}$ & TTA AGT ACG ACT GTC ACT TG & 20 & & & \\
\hline \multirow{2}{*}{ SchVX } & SchVX 678 UP & ATG TCG ACC ACT CCA TCT TC & 20 & \multirow{2}{*}{678} & \multirow{2}{*}{$\mathrm{CP}$} & \multirow{2}{*}{58} \\
\hline & SchVX 678 DN & TTA TTC AGG GGA TGG TAG TA & 20 & & & \\
\hline \multirow{2}{*}{$\mathrm{ZyVX}$} & ZyVX $681 \mathrm{UP}$ & ATG TCT AAC ACT GCA GGA GT & 20 & \multirow{2}{*}{681} & \multirow{2}{*}{$\mathrm{CP}$} & \multirow{2}{*}{58} \\
\hline & ZyVX $681 \mathrm{DN}$ & TCA TTC GGG ACC CGG TAG GA & 20 & & & \\
\hline
\end{tabular}

Bio-Rad, Hercules, CA, USA) with the following program: initial denaturation at $95^{\circ} \mathrm{C}$ for $3 \mathrm{~min} ; 40$ cycles of denaturation at $95^{\circ} \mathrm{C}$ for $30 \mathrm{~s}$, annealing at $55-58^{\circ} \mathrm{C}$ for $30 \mathrm{~s}$, and extension at $72^{\circ} \mathrm{C}$ for $1 \mathrm{~min}$; and final extension at $72^{\circ} \mathrm{C}$ for $10 \mathrm{~min}$. The annealing temperatures used were determined according to Table 1.

Following RT-PCR analysis, two tobamoviruses $(\mathrm{CMMoV}$ and $\mathrm{RCNaV})$ and four potexviruses (CVX, PiVX, SchVX, and ZyVX) were detected in the N. leninghausii f. cristatus sample; OpVX was not detected (Fig. 1C). RT-PCR products for detection of $\mathrm{CMMoV}$ and $\mathrm{RC}$ $\mathrm{NaV}$ were observed at the expected target sizes of 486 and $513 \mathrm{bp}$, respectively, as were those for detection of CVX (678 bp), PiVX (678 bp), SchVX (678 bp), and ZyVX (681 bp) (Table 1, Fig. 1C). Additionally, roughly spherical cactus-infecting viruses, such as TSWV and SCV, were not observed via electron microscopy analysis and were not detected via RT-PCR using specific TSWV CP and SCV $\mathrm{CP}$ primers (data not shown).

To confirm the identification of the detected viruses in the $N$. leninghausii f. cristatus, DNA products obtained by RT-PCR were cloned into the pGEM-T Easy Vector (Promega, Madison, WI, USA) and sequenced by Bioneer Inc (Daejeon, Korea). Sequences were compared with previously reported nucleotide sequences in the NCBI BLAST database. Nucleotide and amino acid sequences were analyzed using DNAMAN software version 5.1 (Lynnon Biosoft, San Ramon, CA, USA). The viral sequences obtained in this study were given the strain name $\mathrm{Nl}$ derived from $N$. leninghausii and were classified into tobamoviruses and potexviruses.

The tobamoviruses $\mathrm{CMMoV}$ and $\mathrm{RCNaV}$ were characterized as follows. The $\mathrm{CP}$ open reading frame (ORF) of CMMoV-Nl (GenBank accession KY581585) shared $99.8 \%$ nucleotide (nt) sequence identity and $99.4 \%$ amino acid (aa) identity with CMMoV-Kr (GenBank accession NC_011803). This CMMoV was isolated from Gymnocalycium mihanovichii in South Korea (Min et al., 2009). The CP ORF of RCNaV-Nl (GenBank accession KY581586) shared $99.4 \%$ and $93.1 \%$ nt sequence identity and $99.4 \%$ and $97.6 \%$ aa identity with $\mathrm{RCNaV}$ (GenBank accession NC_016442) isolated from Aporcactus flagelliformis in South Korea and RCNaV-nopal verdure-2 (GenBank accession KU854932) isolated from Opuntia ficus-indica in Mexico, respectively. As shown in Fig. 2A-2B, CMMoV$\mathrm{Nl}$ and $\mathrm{RCNaV}-\mathrm{Nl}$ are closely related to $\mathrm{CMMoV}$ and $\mathrm{RC}-$ $\mathrm{NaV}$ based on a phylogenetic tree of tobamovirus CPs. The CPs of CMMoV-Nl and $\mathrm{RCNaV}-\mathrm{Nl}$ obtained here shared $60.0 \%$ nt identity and $53.5 \%$ aa identity.

The CP ORFs of the potexviruses CVX-Nl, PiVX$\mathrm{Nl}$, SchVX-Nl, and ZyVX-Nl were similarly analyzed. CVX-Nl (GenBank accession KY581587) shared 77.5\%, $77.1 \%$, and $74.1 \%$ nt sequence identity and $88.9 \%, 87.1 \%$, and $88.4 \%$ aa identity with CVX-Jeju (GenBank accession LC12841) isolated from South Korea and CVX-TW (NC_002815) and CVX-NTU (JF937699) isolated from 
Taiwan, respectively. The CP of CVX-Jeju was itself $97.0 \%$ and $76.3 \%$ identical at the nt level and $94.6 \%$ and $91.6 \%$ identical at the aa level to CVX-TW and CVXNTU, respectively. The three CVX strains TW, NTU, and Jeju clustered together, forming a subgroup. The previously reported CVX strains were isolated from Hylocereus undatus (Kim et al., 2016; Liou et al., 2004). PiVX-Nl (GenBank accession KY581589) shared 98.4\% nt sequence identity and $97.8 \%$ aa identity with PiVX-P37 (GenBank accession NC_024458) isolated from Hylocereus sp. in Taiwan. Sch-
(A)

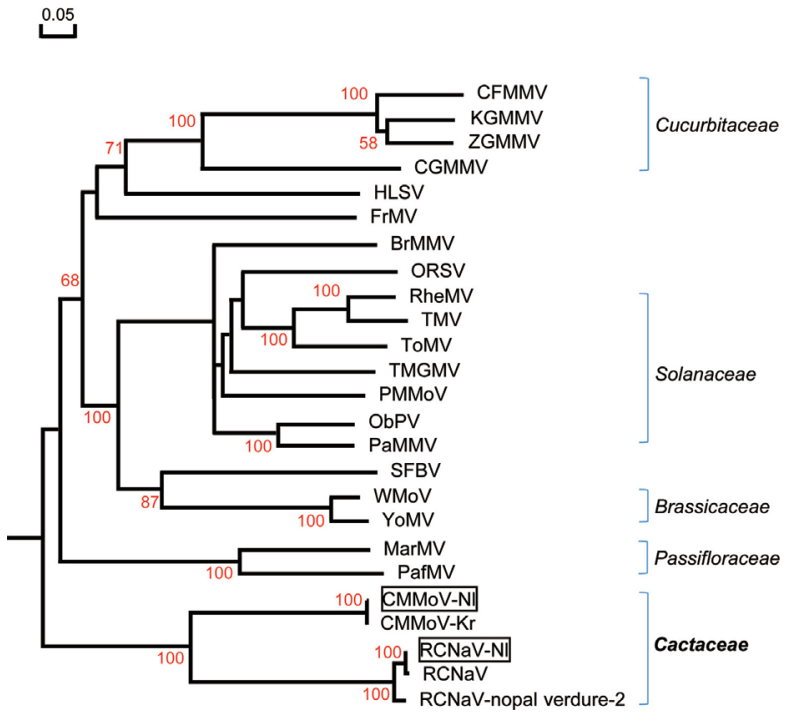

(B)

.0 .5

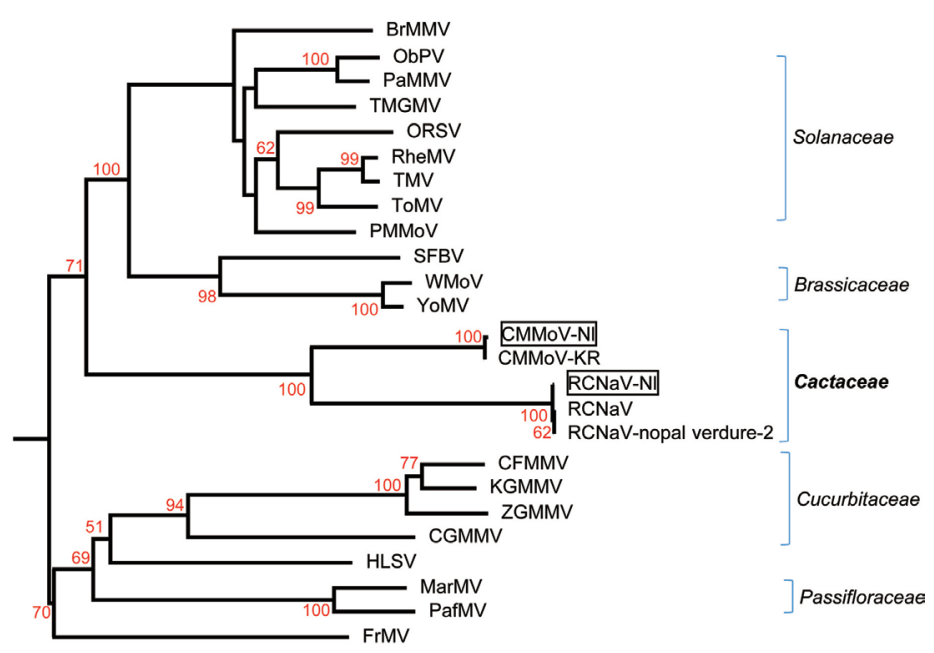

Fig. 2. Phylogenetic tree analyses of the coat proteins (CPs) of the $\mathrm{Nl}$ isolates obtained in this study and of previously reported viruses. (A, B) Phylogenetic trees derived from nt sequences (A) and aa sequences (B) of CMMoV-N1, RCNaV-N1, and other tobamoviruses, (C, D) Phylogenetic trees derived from nt sequences (C) and aa sequences (D) of CVX-N1, RCNaV-N1, SchVX-Nl, ZyVX-N1 and other potexviruses. Multiple sequence alignments were generated using the DNAMAN package, and phylogenetic trees were constructed using the neighbor-joining algorithm based on nt and aa sequence distances derived from multiple alignment. Horizontal branch lengths are proportional to genetic distances, and numbers at each node indicate bootstrap values based on 10,000 bootstrap replicates. The tobamovirus sequences used are derived from brugmansia mild mottle virus (BrMMV), NC_010944; cucumber fruit mottle mosaic virus (CFMMV), NC_002633; cucumber green mottle mosaic virus (CGMMV), NC001801; cactus mild mottle virus (CMMoV-Kr), NC_011803; frangipani mosaic virus (FrMV), NC_014546; hibiscus latent Singapore virus (HLSV), NC_003610; kyuri green mottle mosaic virus (KGMMV), NC_003610; maracuja mosaic virus (MarMV), NC_008716; obuda pepper virus (ObPV), NC_003852; odontoglossum ringspot virus (ORSV), NC_001728; passion fruit mosaic virus (PafMV), NC_015552; paprika mild mottle virus (PaMMV), NC_004106; pepper mild mottle virus (PMMoV), NC_003630; rattail cactus necrosis-associated virus (RCNaV), NC_016442; rattail cactus necrosis-associated virus (RCNaV-nopal verdure-2), KU854932; rehmannia mosaic virus (RheMV), NC_009041; streptocarpus flower break virus (SFBV), NC_008365; tobacco mild green mosaic virus (TMGMV), NC_001556; tobacco mosaic virus (TMV), NC_001367; tomato mosaic virus (ToMV), NC_002692; wasabi mottle virus (WMoV), NC_003355; youcai mosaic virus (YMoV), NC_004422; and zucchini green mottle mosaic virus (ZGMMV), NC_003878. The potexviruses used are derived from alstroemeria virus X (AlsVX), NC_007408; alternanthera mosaic virus (AltMV), NC_007731; asparagus virus 3 (AV3), NC_010416; scallion virus $\mathrm{X}$ (ScaVX), NC_003400; bamboo mosaic virus (BaMV), NC_001642; cactus virus X (CVX-TW), NC_002815; cactus virus X (CVXJeju), LC128411; cactus virus X (CVX-NTU), JF937699; cassava common mosaic virus (CsCMV), NC_001658; clover yellow mosaic virus (ClYMV), NC_001753; cymbidium mosaic virus (CymMV), NC_001812; foxtail mosaic virus (FoMV), NC_001483; hosta virus $\mathrm{X}$ (HVX), NC_011544; hydrangea ringspot virus (HdRSV), NC_006943; lettuce virus X (LeVX), NC_010832; lily virus X (LVX), NC_00719; malva mosaic virus (MalMV), NC_008251; mint virus X (MVX), NC_006948; narcissus mosaic virus (NMV), NC_001441; nerine virus X (NVX), NC_007679; opuntia virus X (OpVX), NC_006060; papaya mosaic virus (PapMV), NC_001748; pepino mosaic virus (PepMV), NC_004067; phaius virus X (PhVX), NC_010295; plantago asiatica mosaic virus (PlAMV), NC_003849; potato aucuba mosaic virus (PAMV), NC_003632; pitaya virus X (PiVX), NC_024458; potato virus X(PVX), NC_011620; schlumbergera virus X (SchVX-K11), NC_011659; schlumbergera virus X (SchVX-nopal verdure 1), KU854929; schlumbergera virus X (SchVX-Palma-PE), KP090203; strawberry mild yellow edge virus (SMYEV), NC_003794; tulip virus X (TVX), NC_004322; white clover mosaic virus (WCIMV), NC_003820; zygocatus virus (ZyVX-B1), NC_006059; and zygocactus virus (ZyVX-P39), JF930326. 
(C)

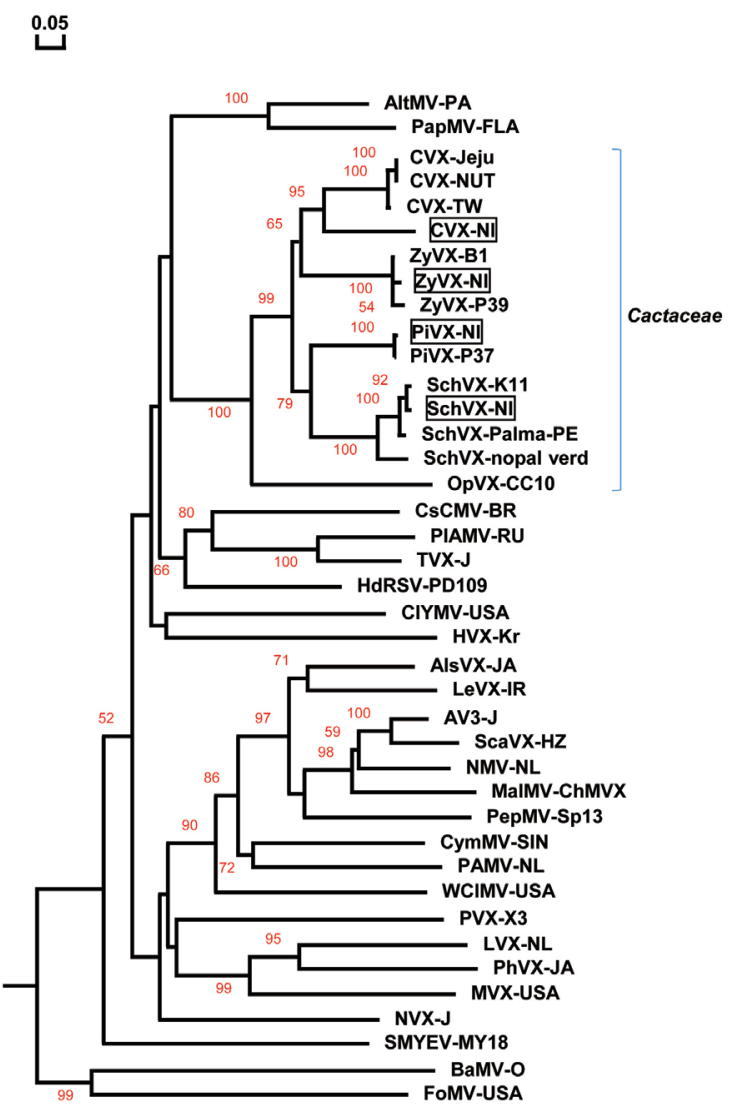

Fig. 2. Continued.

VX-Nl (GenBank accession KY581588) shared 95.7\% and $89.1 \%$ nt sequence identity and $96.9 \%$ aa identity with SchVX-K11 (GenBank accession NC_011659) isolated from Schlumbergera bridgesii in Yugoslavia and SchVX-nopal verdure 1 (KU854929) isolated from Opuntia ficus-indica in Mexico, respectively, and it shared $95.4 \%$ nt identity and $99.6 \%$ aa identity with SchVX-Palma-PE (GenBank KP090203) isolated from Opuntia cochemillifera in Brazil. ZyVX-Nl (GenBank accession KY581590) shared 97.9\% and $95.7 \%$ nt sequence identity and $98.2 \%$ and $96.9 \%$ aa identity with ZyVX-B1 (GenBank accession NC_006059) isolated from Zygocactus sp. in Yugoslavia and ZyVX-P39 (JF930326) isolated from Hylocereus sp.in Taiwan, respectively. The nucleotide sequences of the ZyVX-B1 and P39 CPs were themselves $96.3 \%$ identical at the nt level and 96.9\% identical at the aa level. As shown in Fig. 2C-D, the four potexviruses detected in this study, CVX-Nl, PiVX$\mathrm{Nl}$, SchVX-Nl, and ZyVX-Nl, each clustered in different subgroups with their respective previously reported CVX, PiVX, SchVX and ZyVX strains.

Most cactus-infecting viruses, such as CVX, OpVX,
(D)

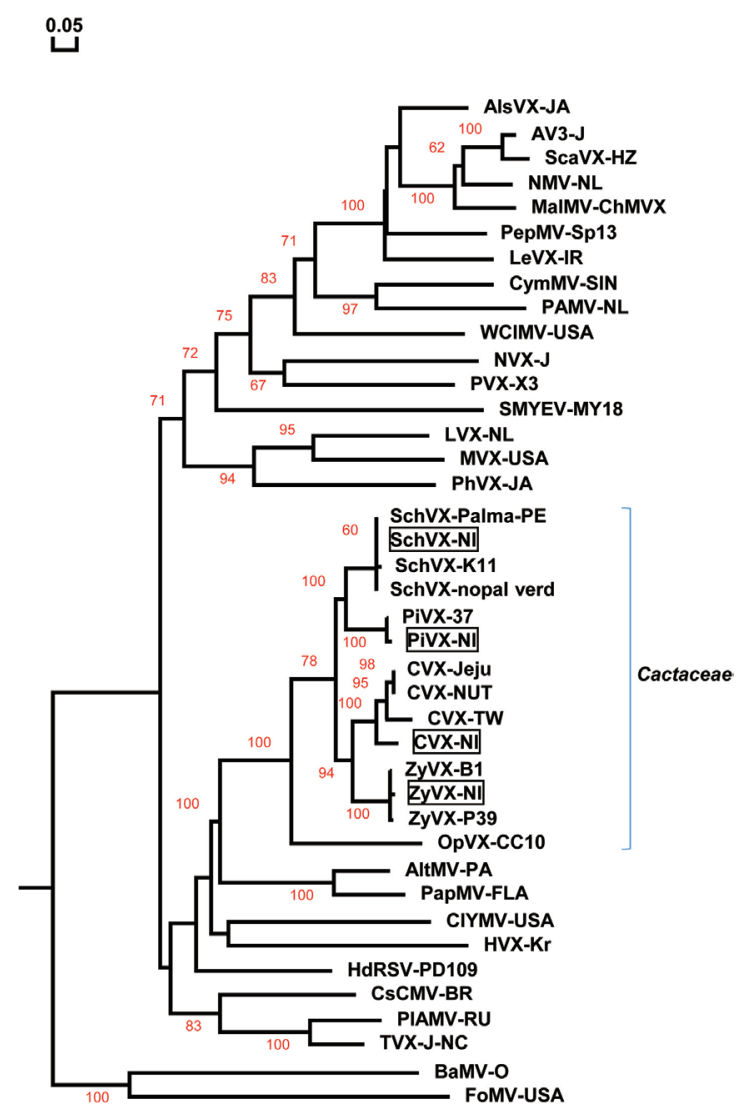

SOV, SCV, and TSWV, have been reported in the USA, which is one of the countries that exports cacti into South Korea. $\mathrm{CMMoV}, \mathrm{CVX}$, and $\mathrm{RCNaV}$ were previously reported in Gymnocalycium mihanovichii, Hylocereus spp., and Aporcactus flagelliformis, respectively, in South Korea (Kim et al., 2012; Min et al., 2006). Grafting is generally used to reproduce and propagate cactus plants, but viruses can be transmitted easily through this method (Bausher, 2013; Estrada-Luna et al., 2002; de Medeiros et al., 2006; Maliareko and Mudrak, 2013; Min et al., 2006). The $N$. leninghausii $\mathrm{f}$. cristatus collected from the cactus farms in this study was also produced using the grafting method. Consequently, co-infection with various viruses (six species) in $N$. leninghausii f. cristatus may be related to grafting. This study demonstrates that $N$. leninghausii f. cristatus can be co-infected with at least six different viruses (CMMoV, CVX, RCNaV, PiVX, SchVX, and ZyVX).

\section{Acknowledgments}

This study was supported by a sabbatical year research 
grant from Seoul Women's University (2016), and by grants (2014M3A9B8022821, 2015R1D1A1A01060614) from the National Research Foundation in Korea.

\section{References}

Aragao, F., Marinho, V. and Kitajima, E. 1993. Cactus virus X in Cactaceae in Brazil and a novel method to purify it directly from cactus tissues. Fitopatol. Bras. 18:112-117.

Bausher, M. G. 2013. Serial transmission of plant viruses by cutting implements during grafting. HortSceince 48:37-39.

Chessin, M. and Lesemann, D. 1972. Distribution of cactus viruses in wild plants. Phytopathology 62:97-99.

Estrada-Luna, A. A., Lopez-Peralta, C. and Cardenas-Soriano, E. 2002. In vitro micrografting and the histology of graft union formation of selected species of prickly pear cactus (Opuntia spp.). SciHort 92:317-327.

de Medeiros, L. A., de Ribeiro, R. C. S., Gallo, L. A., de Oliveira, E. T. and Dematte, M. E. S. P. 2006. In vitro propagation of Notocactus magnificus. Plant Cell Tissue Organ Cult. 84:165169.

Hausbeck, M. K., Welliver, R. A., Derr, M. A. and Gildow, F. E. 1992. Tomato spotted wilt virus survey among greenhouse ornamentals in Pennsylvania. Plant Dis. 76:795-800.

Kim, J. S., Park, C. Y., Nam, M., Lee, J. S., Kim, H. G. and Lee, S. H. 2016. First report of Cactus virus $X$ infecting Hylocereus undatus in Korea. Plant Dis. 100:2544.

Kim, N. R., Hong, J. S., Song, Y. S., Chung, B. N., Park, J. W. and Ryu, K. H. 2012. The complete genome sequence of a member of a new species of tobamovirus (rattail cactus necrosis-associated virus) isolated from Aporcactus flagelliformis. Arch. Virol. 157:185-187.

Koenig, R., Pleij, C. W. A., Loss, S., Burgermeister, W., Aust, H. and Schiemann, J. 2004. Molecular characterisation of potexviruses isolated from three different genera in family Cactaceae. Arch. Virol. 149:903-914.

Lim, M., Min, B., Ryu, K. and Choi, S. 2016. Sequence analysis of saguaro cactus carmovirus isolated from the grafted cactus in Korea. In: Proceedings of the 14th International Symposium on Virus Diseases of Ornamental Plants (26-29th June, 27). National of University of Singapore, Singapore.

Liou, M. R., Chen, Y. R. and Liou, R. F. 2004. Complete nucleotide sequence and genome organization of a Cactus virus $\mathrm{X}$ strain from Hylocereus undatus (Cactaceae). Arch. Virol. 149:1037-1043.

Liou, M. R., Hung, C. L. and Liou, R. F. 2001. First report of Cactus virus $X$ on Hylocereus undatus (Cactaceae) in Taiwan. Plant Dis. 85:229.

Maliarenko, V. M. and Mudrak, T. P. 2013. Cactus viruses in fasciated plants. Biologija 59:213-218.

Milbrath, G. M. and Nelson, M. R. 1972. Isolation and characterization of a virus from saguaro cactus. Phytopathology 62:739-742.

Milbrath, G. M., Nelson, M. R. and Wheeler, R. E. 1973. The distribution and electron microscopy of viruses of cacti in southern Arizona. Phytopathology 63:1133-1139.

Min, B. E., Chung, B. N., Kim, M. J., Ha, J. H., Lee, B. Y. and Ryu, K. H. 2006. Cactus mild mottle virus is a new cactusinfecting tobamovirus. Arch. Virol. 151:13-21.

Min, B. E., Song, Y. S. and Ryu, K. H. 2009. Complete sequence and genome structure of cactus mild mottle virus. Arch. Virol. 154:1371-1374.

Suaste-Dzul, A., Rojas-Martinez, R. I., Ochoa-Martinez, D., Zavaleta-Mejia, E., Perez-Brito, D., Hernandez-Juarez, C. and Rodriguez-Martinez, D. 2012. Virus associated with thickening of the cladodes of prickly pear (Opuntia ficus-indica Mill.). J. Biotechnol. Biodivers. 3:100-107. 